\title{
Scurvy in the Postoperative Oropharyngeal Cancer Patient
}

\author{
Kazuharu Kamachi1, Kazuko Doi², Momoka Ishida', Masaharu Miyahara', Shinya Kimura ${ }^{3}$ \\ ${ }^{1}$ Department of Internal Medicine, Karatsu Red Cross Hospital, Japan \\ ${ }^{2}$ Department of Dermatology, Karatsu Red Cross Hospital, Japan \\ ${ }^{3}$ Division of Hematology, Respiratory Medicine and Oncology, Department of Internal Medicine, Faculty of Medicine, Saga University, \\ Saga, Japan \\ Email:shkimu@cc.saga-u.ac.jp
}

How to cite this paper: Kamachi, K., Doi, K., Ishida, M., Miyahara, M. and Kimura, S. (2016) Scurvy in the Postoperative Oropharyngeal Cancer Patient. International Journal of Clinical Medicine, 7, 577-584. http://dx.doi.org/10.4236/ijcm.2016.79063

Received: July 28, 2016

Accepted: August 21, 2016

Published: August 25, 2016

Copyright $\odot 2016$ by authors and Scientific Research Publishing Inc. This work is licensed under the Creative Commons Attribution International License (CC BY 4.0).

http://creativecommons.org/licenses/by/4.0/

\begin{abstract}
Scurvy is now an almost forgotten disease, but it hasn't yet disappeared entirely. Here, we report the case of a patient with scurvy who presented with multiple hemorrhages about 5 years after undergoing pharyngeal surgery and radiochemotherapy for oropharyngeal cancer. This 60 -year-old man was admitted to our hospital because of sudden onset of dyspnea and purpura. A physical examination and computed tomography revealed multifocal hemorrhages, namely, purpuras and petechiae on the legs and intramuscular and alveolar hemorrhages. Coagulation tests indicated a normal bleeding time and mild extension of the activated partial thromboplastin time. The coagulation factor activities were not low enough to account for such severe hemorrhages. No new hemorrhages were observed after admission. On questioning about his past eating habits, the patient reported having long had an extremely unbalanced diet, namely, a diet that was composed largely of carbohydrates with few fresh fruits and vegetables. This was due to the development of mechanical dysphagia after the operation. Since his vitamin C level was $0.5 \mu \mathrm{g} / \mathrm{mL}$ (normal range: $5.5-16.8 \mu \mathrm{g} / \mathrm{mL}$ ), a diagnosis of scurvy was established. Thus, scurvy can still occur in modern times due to poor eating habits that arise from unusual settings. We must keep in mind that scurvy may be the cause when a patient presents with an apparently inexplicable tendency to hemorrhage.
\end{abstract}

\section{Keywords}

Scurvy, Vitamin C, Oropharyngeal Cancer

\section{Introduction}

Scurvy is a disease that was extremely prevalent among sailors during the Age of Dis- 
covery between the 15th and 18th centuries. It was not clear until the 19th century that scurvy was the result of severe vitamin $C$ deficiency [1]. Since vitamin $C$ is an enzyme cofactor that is needed for collagen synthesis, long-term vitamin $\mathrm{C}$ deficiency induces connective tissue fragility and multiple organs become prone to hemorrhages after even very slight physical pressure or damage [2]. Our thorough understanding of the importance of vitamin $\mathrm{C}$ consumption has led in modern times to supplementation of commercial foods with vitamin C. Consequently, although scurvy still occurs in developing countries, it is an almost forgotten disease in industrialized countries. This is particularly true for Japan because it has a culture of eating raw food. We report here the case of a patient with scurvy who presented with multiple hemorrhages about 5 years after undergoing pharyngeal surgery for oropharyngeal cancer.

\section{Case Presentation}

A 60-year-old man was admitted to our hospital in January 2016 because of sudden onset of dyspnea and purpura. The patient had felt as usual until 1 month before admission, at which point he noticed multifocal petechiae on his legs. Over the next few days, the lesions increased and his left calf swelled painfully. Several days before admission, the patient became aware of purpura on the left side of his abdomen, which was causing intermittent pain. On the day of admission, he developed dyspnea. The history of the patient included surgery for oropharyngeal cancer in 2007. The cancer relapsed in 2010 and the patient underwent a second operation that was then followed by radiochemotherapy. Thereafter, relapse was not detected. The operations meant that the patient had to keep using an artificial saliva aerosol. The patient did not have a tendency towards hemorrhage as a child and there was no familial history of coagulation disorders. At the time of the most recent presentation, the patient had retired from his occupation as a fisherman and lived alone. Starting at the age of 20 years, the patient had consumed alcohol socially and smoked two packs of cigarettes a day. However, the patient stopped smoking at the age of 51 years, when he was first admitted for oropharyngeal cancer.

On examination, the patient was awake and alert. His temperature was $36.2^{\circ} \mathrm{C}$, his blood pressure was $106 / 68 \mathrm{mmHg}$, his pulse was 52 beats per minute, and his oxygen saturation while breathing ambient air was $88 \%$. His palpebral conjunctivae were anemic and no adventitious lung sounds were heard. Purpuras were observed along with tender swellings on the left lower side of his abdomen, his left calf, and his left ankle. There were also purpuras on the periungual areas of his toes and petechiae on his legs (Figure 1).

Hematological tests revealed pancytopenia: the white blood cell count was $3.4 \times$ $109 / \mathrm{L}$ and consisted of $82 \%$ neutrophils, $2.4 \%$ eosinophils, $0 \%$ basophils, $3.6 \%$ monocytes, and $12.5 \%$ lymphocytes. Moreover, the hemoglobin concentration was $10.6 \mathrm{~g} / \mathrm{dL}$, and the platelet count was $137 \times 109 / \mathrm{L}$. The bleeding time was normal and blood coagulation tests revealed mild extension of activated partial thromboplastin time (APTT) without extension of prothrombin time (PT) and a mild increase in the levels of 


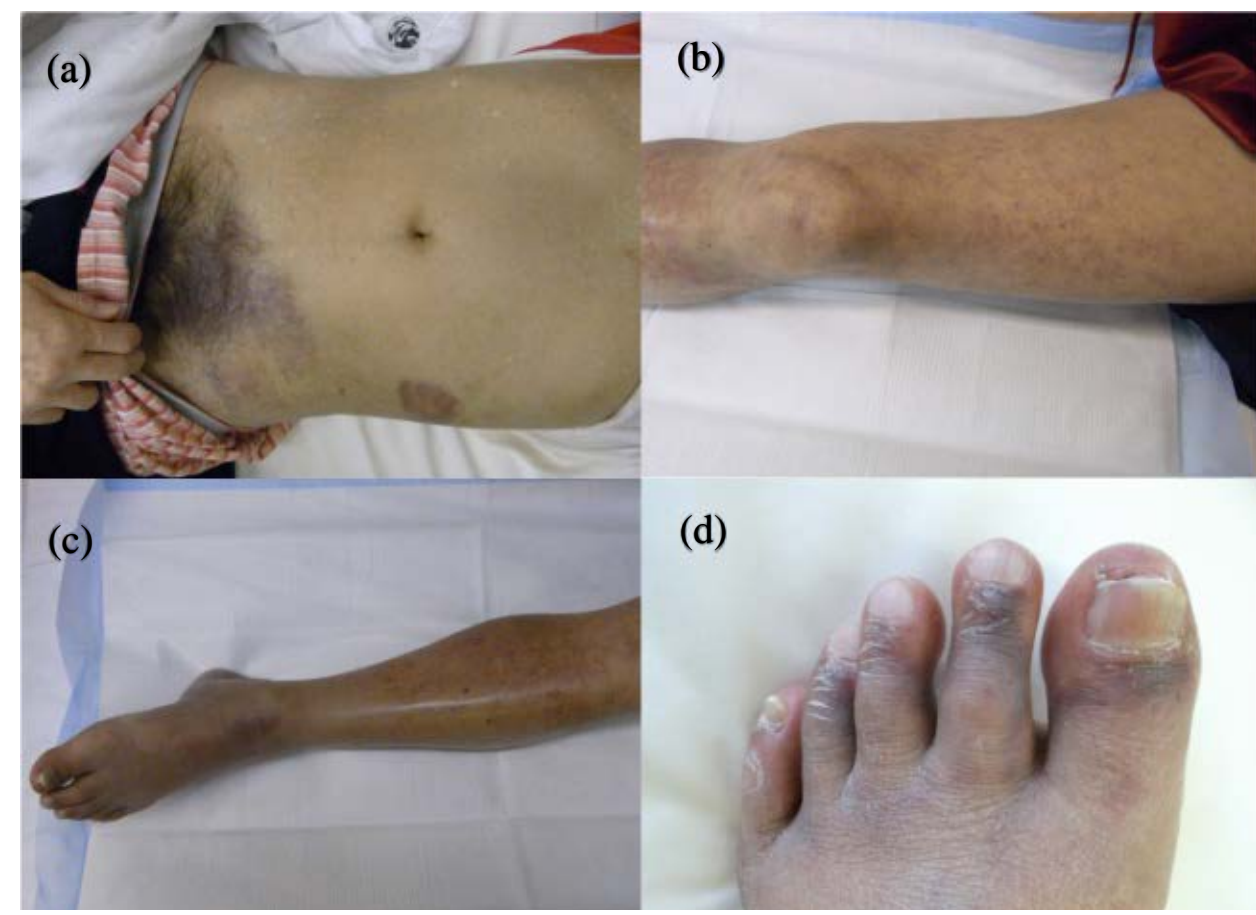

Figure 1. Physical manifestations. The patient had multiple purpuras and petechiae, which indicates an obvious tendency to hemorrhage. (a) Purpura of the abdominal wall; (b) petechiae of the legs; (c) swelling of the left calf; (d) purpuras on the periungual areas of the toes.

fibrinogen, fibrin degradation products, and D-dimer. Serological and biochemical tests showed that the C-reactive protein, indirect bilirubin (id-BIL), and lactate dehydrogenase $(\mathrm{LDH})$ levels were high at $7.5 \mathrm{~g} / \mathrm{dL}, 1.44 \mathrm{mg} / \mathrm{dL}$, and $300 \mathrm{U} / \mathrm{L}$, respectively. In terms of electrolytes, the sodium level was low $(128 \mathrm{mmol} / \mathrm{L})$, but the potassium, calcium, and chloride levels were normal. The blood levels of free T4 and thyroid-stimulating hormone (TSH) were normal. The laboratory test results of the patient at admission are shown in Table 1.

Chest radiography showed a mass shadow on the right upper lobe. Contrast-enhanced computed tomography (CT) of the chest found that this shadow was a solitary mass that had a cavity inside it. CT also detected ground-glass opacities on the right inferior lobe that could be alveolar hemorrhages. CT of the trunk and legs detected multiple intramuscular hemorrhages on the patient's left abdominal oblique muscle and the muscles of both legs (Figure 2).

Curiously, the patient did not develop further hemorrhages after admission. Initially, we wondered whether the patient might have some kind of acquired coagulation disorder because of the sudden onset of the hemorrhages and the presence of lung mass, which could indicate the presence of a malignant cancer. However, the activities of VIII and IX coagulation factors were sufficient. Moreover, although the XI, XII, and XIII levels were overall slightly under the lower limit of normal, the weak decrease was considered to be unlikely to account for the severity of the patient's hemorrhages.

We also speculated whether the patient had a collagen disease that could induce 
Table 1. Laboratory data on admission.

\begin{tabular}{|c|c|c|c|c|c|c|c|c|}
\hline \multicolumn{3}{|c|}{ Complete blood count } & \multicolumn{3}{|c|}{ Biochemistry } & \multicolumn{3}{|c|}{ Coagulation } \\
\hline WBC & 3350 & $/ \mu \mathrm{L}$ & TP & 6.3 & $\mathrm{~g} / \mathrm{dL}$ & $\mathrm{PT}$ & 13.1 & $\sec$ \\
\hline $\mathrm{Neu}$ & 82 & $\%$ & Alb & 3.3 & $\mathrm{~g} / \mathrm{dL}$ & PT & 69 & $\%$ \\
\hline Lym & 12.5 & $\%$ & T-Bil & 1.6 & $\mathrm{mg} / \mathrm{dL}$ & APTT & 43.4 & $\mathrm{sec}$ \\
\hline Mono & 3.6 & $\%$ & D-Bil & 0.16 & $\mathrm{mg} / \mathrm{dL}$ & $\mathrm{Fib}$ & 437 & $\mathrm{mg} / \mathrm{dL}$ \\
\hline Eosino & 2.4 & $\%$ & AST & 17 & $\mathrm{U} / \mathrm{L}$ & FDP & 13.6 & $\mu \mathrm{g} / \mathrm{mL}$ \\
\hline Baso & 0 & $\%$ & ALT & 9 & $\mathrm{U} / \mathrm{L}$ & D-dimer & 4.7 & $\mu \mathrm{g} / \mathrm{mL}$ \\
\hline $\mathrm{RBC}$ & $340 \times 10^{4}$ & $/ \mu \mathrm{L}$ & $\mathrm{LDH}$ & 300 & $\mathrm{U} / \mathrm{L}$ & & & \\
\hline $\mathrm{Hb}$ & 10.6 & $\mathrm{~g} / \mathrm{dL}$ & rGTP & 30 & $\mathrm{U} / \mathrm{L}$ & & & \\
\hline Ret & 26 & $\%$ & ALP & 272 & $\mathrm{U} / \mathrm{L}$ & & & \\
\hline $\mathrm{Ht}$ & 31 & $\%$ & CK & 154 & $\mathrm{U} / \mathrm{L}$ & & & \\
\hline \multirow[t]{8}{*}{ PLT } & $13.7 \times 10^{4}$ & $/ \mu \mathrm{L}$ & BUN & 13 & $\mathrm{mg} / \mathrm{dL}$ & & & \\
\hline & & & $\mathrm{Cr}$ & 0.86 & $\mathrm{mg} / \mathrm{dL}$ & & & \\
\hline & & & $\mathrm{Na}$ & 128 & $\mathrm{mmol} / \mathrm{L}$ & & & \\
\hline & & & $\mathrm{K}$ & 4.8 & $\mathrm{mmol} / \mathrm{L}$ & & & \\
\hline & & & $\mathrm{Cl}$ & 96 & $\mathrm{mmol} / \mathrm{L}$ & & & \\
\hline & & & CRP & 7.5 & $\mathrm{mg} / \mathrm{dL}$ & & & \\
\hline & & & TSH & 56 & $\mu \mathrm{IU} / \mathrm{mL}$ & & & \\
\hline & & & F-T4 & 0.8 & $\mu \mathrm{IU} / \mathrm{mL}$ & & & \\
\hline
\end{tabular}
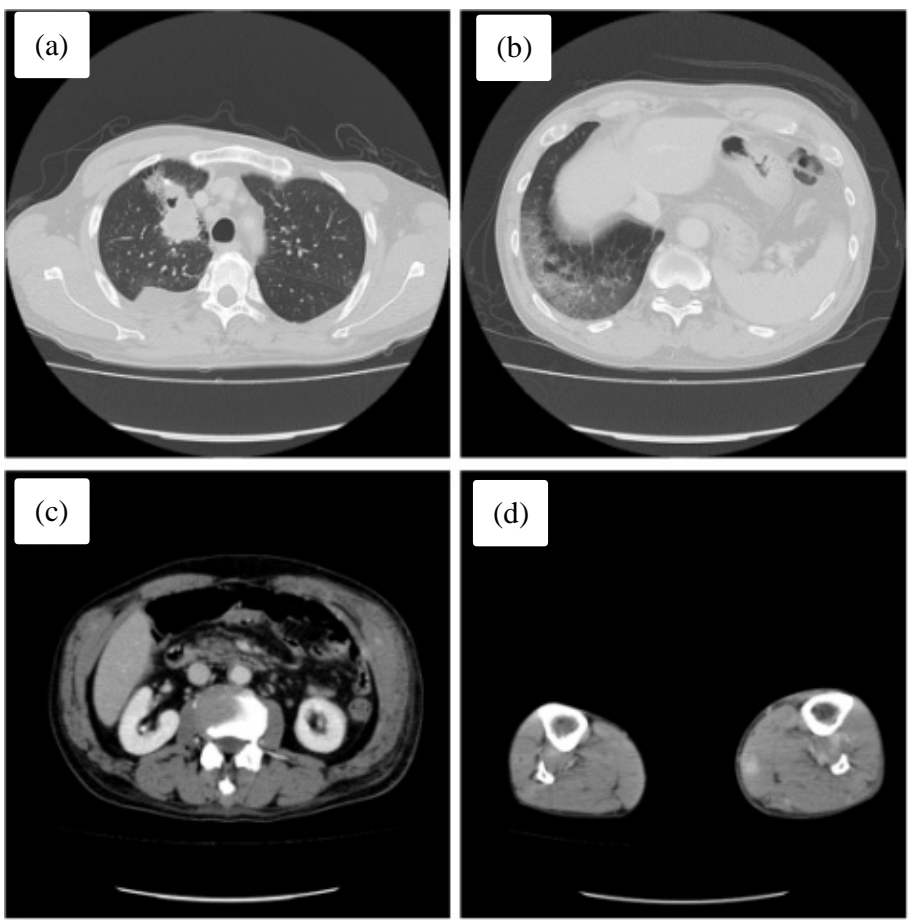

Figure 2. Contrast-enhanced computed tomography findings. (a) Lung mass on the right upper lobe; (b) ground-glass opacities on the right inferior lobe that may indicate alveolar hemorrhages; (c) intramuscular hemorrhage of the left abdominal oblique muscles; (d) intramuscular hemorrhage of the bilateral calves. 
microangiopathy of the small vessels, such as antineutrophil cytoplasmic antibody (ANCA)-related vasculitis, systemic lupus erythematosus, or malignant rheumatoid arthritis. We obtained a skin biopsy from the purpura on the patient's left calf: histopathology revealed extravasation of red blood cells in the superficial to middle dermis but no infiltrating inflammatory cells around the small vessels. Thus, vasculitis was not indicated. The histopathological diagnosis was a purpura compatible. Thus, none of these tests led to an explanation for the cause of the multiple hemorrhages of the patient.

Another puzzling finding was the laboratory result of pancytopenia. However, this together with the slight increase in LDH and id-BIL led us to suspect hemolysis with an ineffective hematopoiesis such as myelodysplastic syndrome and megaloblastic anemia due to vitamin B12 and/or folic acid deficiency. Thus, further laboratory tests were requested. The test results are shown in Table 2.

The tests showed low levels of vitamin B12 and folic acid level despite the fact that the patient did not have a history of gastrectomy. This led to suspicion of a poor diet and thus a careful history of the patient's daily diet was taken. Surprisingly, the diet of the patient had become extremely unbalanced ever since he underwent the second operation for the oropharyngeal cancer in 2010: In the 5 years before admission, the patient had only eaten rice or tofu for breakfast and Japanese or Chinese-style noodles for lunch and dinner. Thus, the intake of fresh fruits, vegetables, and meat by the patient had been very limited for several years. This explained the vitamin B12 and folic acid deficiencies and was suggestive of other vitamin deficiencies, especially vitamin C deficiency. Indeed, testing for vitamin C 11 days after admission revealed a level of 0.5 $\mu \mathrm{g} / \mathrm{mL}$ (normal range: $5.5-16.8 \mu \mathrm{g} / \mathrm{mL}$ ). Thus, a diagnosis of scurvy was established.

The patient was started on $1000 \mathrm{mg}$ of vitamin C per day for the first 3 days, after which $400 \mathrm{mg}$ was given per day for 2 months. In addition, a multivitamin supplement that included vitamin B12 and folic acid was administered. The purpuras and petechiaehe and the pancytopenia of the patient disappeared gradually. Since the patient's tendency to hemorrhage has been resolved, he is currently scheduled to undergo a bronchoscopy to examine the lung mass.

Table 2. Additional laboratory data obtained a few days after admission.

\begin{tabular}{cccccc}
\hline \multicolumn{2}{c}{ Coagulation factors } & \multicolumn{3}{c}{ Biochemistry } \\
\hline VIII & $152.5(60-140)$ & $\%$ & Fe & 63 & $\mu \mathrm{g} / \mathrm{dL}$ \\
IX & $78.5(60-140)$ & $\%$ & Ferritin & 177 & $\mathrm{ng} / \mathrm{mL}$ \\
XI & $66(75-145)$ & $\%$ & Vitamin B12 & 116 & $\mathrm{pg} / \mathrm{mL}$ \\
XII & $42(50-150)$ & $\%$ & Folic acid & 3.9 & $\mathrm{ng} / \mathrm{mL}$ \\
XIII & $59(70-140)$ & $\%$ & & & \\
& & & LA & 1.05 & \\
vWF antigen & $150(50-155)$ & $\%$ & ANA & $<40$ & \\
vWF activity & $178(60-170)$ & $\%$ & RF & 0 & $\mathrm{IU} / \mathrm{mL}$ \\
& & & P-ANCA & $<1.0$ & $\mathrm{U} / \mathrm{mL}$ \\
& & & C-ANCA & $<1.0$ & $\mathrm{U} / \mathrm{mL}$ \\
\hline
\end{tabular}




\section{Discussion}

Scurvy was first described by the Portuguese sailor Vasco da Gama during his voyage from Lisbon to India via Africa in 1498. Most of his crew became afflicted by this mysterious and frightening disease, which was characterized by poor wound healing, generalized edema, and life-threatening hemorrhages. In 1753, Sir James Lind, a ship's surgeon in the British Navy, found that if ships carried citrus fruits such as limes, oranges, and lemons, their sailors were less likely to develop scurvy. He reported on the basis of a controlled clinical trial (the first ever to be reported) that eating limes would protect the sailors from scurvy. It was only in 1932 that Szent-Györgyi in Hungary and C.G. King in the United States of America proved that vitamin C is the key substance that prevents scurvy. Vitamin $\mathrm{C}$ was then given the name "ascorbic acid", meaning a substance effective against scurvy [2].

Today, scurvy is an almost forgotten disease and most physicians in industrialized countries will never encounter a patient with it. However, it is still occasionally reported. In 2006, Olmed et al. reported 12 cases of scurvy that had been diagnosed at the Mayo Clinic between 1976 and 2002. Ten of these cases associated with alcohol abuse, illicit drug use, and severe mental disorders (e.g., depression or dementia). Moreover, five patients had food faddism or avoided products that contained vitamin $\mathrm{C}$ because of an alleged intolerance or allergy [3]. Today, patients with these factors remain at risk of developing scurvy. Indeed, our literature search revealed three reports of cases of scurvy in Japan in the last 20 years [4]-[6]. In all three reports, the patients had the risk factors described by Olmed et al. In our case, the patient developed scurvy because he had mechanical dysphagia after undergoing surgery for oropharyngeal cancer. This caused the patient to prefer eating soft foods that were easy to swallow. Thus, the diet of our patient for several years before admission consisted largely of carbohydrates; vitamin C-containing products were seldom ingested and thus the patient developed scurvy.

Vitamin C plays an essential role in the synthesis of collagens, which are major constituents of the extracellular matrix in the connective tissues. These collagens are thus important components of the physical barrier against external pressure and are responsible for maintaining organ form. Vitamin $\mathrm{C}$ is an enzyme cofactor for collagen prolyl hydroxylases, which catalyze the formation of intra-and inter-chain disulfide bonds during collagen synthesis [7] [8]. Thus, vitamin C deficiency inhibits collagen synthesis and results in tissue fragility, especially in the skin, gums, mucus membranes, and blood vessels.

Scurvy associates with a wide variety of cutaneous manifestations, including xerosis, ecchymosis, edema, poor wound healing, and gingival hemorrhage. "Perifollicular hemorrhage" and "corkscrew hair" are particularly characteristic manifestations of scurvy; their detection should arouse suspicion of the disease. Perifollicular hemorrhage is hemorrhage from a perifollicular site, especially on the legs, where hydrostatic pressure and hair movement due to mechanical irritation rupture the fragile perifollicular capillaries. Corkscrew hair is characterized by coiled body hairs that have a swan-neck 


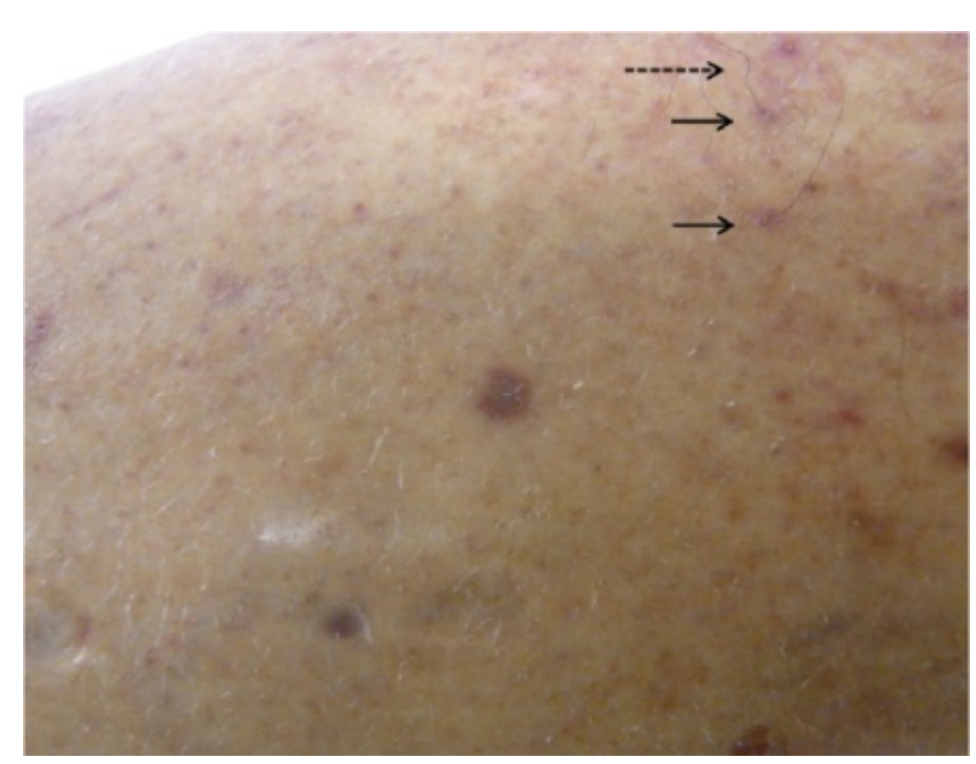

Figure 3. Enlarged photo of the left femoral skin, "perifollicular hemorrhages" (arrows) and "corkscrew hair" (dotted arrow) were observed after the patient was inspected carefully.

shape. This reflects the inhibition of disulphide bonding during hair formation that is caused by vitamin C deficiency [9] [10]. On closer examination of our patient after the diagnosis, we found both perifollicular hemorrhages and corkscrew hairs (Figure 3).

To develop scurvy, multiple years of vitamin C deficiency are needed. Although today such a situation is very unlikely to occur, our case shows clearly that scurvy can still arise in even the 21 th century. The culprit is a prolonged unbalanced diet that was adopted for various reasons. Thus, when we encounter a patient with an inexplicable tendency to bleed, vitamin $\mathrm{C}$ deficiency should be included in the differential diagnosis. Thus, such patients should be asked about their dietary history and carefully inspected for the characteristic skin manifestations of scurvy.

\section{Conflicts of Interest}

The authors declare that they have no conflicts of interest to declare.

\section{References}

[1] Pimentel, L. (2003) Scurvy: Historical Review and Current Diagnostic Approach. American Journal of Emergency Medicine, 21, 328-332. http://dx.doi.org/10.1016/S0735-6757(03)00083-4

[2] Hirschmann, J.V. and Raugi, G.J. (1999) Adult Scurvy. Journal of the American Academy of Dermatology, 41, 895-906. http://dx.doi.org/10.1016/S0190-9622(99)70244-6

[3] Olmedo, J.M., Yiannias, J.A., Windgassen, E.B. and Gornet, M.K. (2006) Scurvy: A Disease Almost Forgotten. International Journal of Dermatology, 45, 909-913. http://dx.doi.org/10.1111/j.1365-4632.2006.02844.x

[4] Haraguchi, G., Yamada, S., Tanaka, M., Hashimoto, Y., Kakuta, T., Kishi, Y., et al. (1997) A Case of Scurvy Rarely Encountered in Japan. Vascular Medicine, 2, 143-146. 
[5] Niwa, T., Aida, N., Tanaka, Y., Tanaka, M., Shinomi, M. and Machida, J. (2012) Scurvy in a Child with Autism: Magnetic Resonance Imaging and Pathological Findings. Journal of Pediatric Hematology/ Oncology, 34, 484-487. http://dx.doi.org/10.1097/MPH.0b013e318236c519

[6] Ohta, A., Yoshida, S., Imaeda, H., Ohgo, H., Sujino, T., Yamaoka, M., et al. (2013) Scurvy with Gastrointestinal Bleeding. Endoscopy, 45.

[7] Du, J., Cullen, J.J. and Buettner, G.R. (2012) Ascorbic Acid: Chemistry, Biology and the Treatment of Cancer. Biochimica et Biophysica Acta, 1826, 443-457. http://dx.doi.org/10.1016/j.bbcan.2012.06.003

[8] Léger, D. (2008) Scurvy: Reemergence of Nuturitional Deficiencies. Canadian Family Physician, 54, 1403-1406.

[9] Walters, R.W. and Grichnik, J.M. (2006) Follicular Hyperkeratosis, Hemorrhage, and Corkscrew Hair. Archives of Dermatology, 142, 658.

http://dx.doi.org/10.1001/archderm.142.5.658

[10] Kocak, M., Akbay, G., Eksioglu, M. and Astarci, M. (2003) Case 2: Sudden Ecchymosis of the Legs with Feelings of Pain and Weakness. Diagnosis: Adult Scurvy. Clinical and Experimental Dermatology, 28, 337-338. http://dx.doi.org/10.1046/j.1365-2230.2003.01259.x

Submit or recommend next manuscript to SCIRP and we will provide best service for you:

Accepting pre-submission inquiries through Email, Facebook, LinkedIn, Twitter, etc. A wide selection of journals (inclusive of 9 subjects, more than 200 journals)

Providing 24-hour high-quality service

User-friendly online submission system

Fair and swift peer-review system

Efficient typesetting and proofreading procedure

Display of the result of downloads and visits, as well as the number of cited articles Maximum dissemination of your research work

Submit your manuscript at: http://papersubmission.scirp.org/ 